\title{
Vitrification and its impact on oocyte structures. A review
}

\author{
Alma López ${ }^{1}$, Miguel Betancourt ${ }^{2}$ and Fahiel Casillas ${ }^{3 *}$ \\ ${ }^{1}$ PHD in Biological and Health Sciences, Mexico \\ ${ }^{2}$ Department of Health Sciences, Mexico \\ ${ }^{3}$ Department of Biology of Reproduction, Mexico
}

*Corresponding author: Fahiel Casillas, Autonomous Metropolitan UniversityIztapalapa Unit, CDMX, Mexico.

Received Date: December 12, 2019

Published Date: January 17, 2020

\section{Abstract}

The vitrification of oocytes and embryos produces structural damage caused by the cytotoxicity of the cryoprotective agents (CPAs). Some of these damages occur in the cell plasma membrane, cytoskeleton and genetic material, which might result in the formation of aneuploidies. The toxicity produced by the use of CPAs during vitrification can cause alterations in microfilaments (MF), microtubules (MT) and chromatin (CR), affecting not only cell viability, maturation, fertilization and embryonic development (ED), but also the genetic integrity that will result in the formation of aneuploidies. The latter can result in spontaneous abortions and/or the absence of a term pregnancy, and if an opposite case arises, the birth of offspring with chromosomal aberrations will affect the organism development.

\section{Introduction}

Vitrification, as a method of cell cryopreservation, has been considered a very important tool for Assisted Reproduction Technologies (ART), improving the reproductive quality of economic important species for animal production and, in humans for subfertility treatments [1,2]. Vitrification is used in oocytes and embryos of different species such as pigs [3], sheep [4], cattle [5], humans $[6,7]$, among others, since it has been superior to slow freezing $[8,9]$.

Since the first vitrification success reported in 1985 [10], its effects on different domestic species and cell structures have been studied [11-15]. Although vitrification is a technique widely used for gametes preservation, multiple cell structures have been reported that, to a greater or lesser extent, suffer damage derived from the cryoprotective agents (CPAs). Therefore, the success of this method will be largely reflected by the reduction of the damage caused by the intracellular formation of ice crystals and the use of appropriate concentrations of CPAs.

\section{Cell Structure Damage}

\section{Plasma membrane}

It is important to highlight that the structure and composition of plasma membranes determine the main cellular events that take place during cryopreservation processes. The plasma membrane of the eukaryotic cell is mainly composed of amphipathic lipids, proteins and carbohydrates, with varying proportions according to cell type and animal species [16]. The CPAs used for the maintenance of cells at low temperatures must have the ability to penetrate the cell membranes in order to diffuse and take place inside the cell, remaining in a solid vitreous state. It is important to consider that the determination of the concentration of the CPAs is critical, since it will depend on that the role of protective agent, and thus, reducing its toxicity.

CPAs toxicity is mainly due to two causes. First is the chemical reaction performed in the cells before cryopreservation, and second is the chemical effect caused by the change of osmosis in the freezing solutions. In addition to this, the decrease in the freezing point (derived from the concentration of the CPAs mixture) is related to their permeability, which can cause osmotic stress before vitrification [17]. Therefore, when seeking to reduce the risk of toxicity damage, it is important to consider implementing the optimal CPAs, appropriate exposure time and temperature [18].

CPAs do not have the same membrane diffusion capacity in all cell types, which is why cell membranes are one of the structures that suffer the most damage during cryopreservation due to the 
loss of fluidity of their lipid components, reducing their ability to expansion during rehydration [19]. It has been proposed that an important damage factor caused by CPAs in oocytes plasma membranes and embryos is derived from protein denaturation. It has been attributed that the toxic effects of vitrification solutions are due to the strong interaction between permeable CPAs, particularly dimethyl sulfoxide (DMSO) and water, which can cause damage by affecting the hydration of proteins [20]. Due to the interaction of these permeable agents with the hydration layer of water molecules (or solvation layer) that surrounds protein surfaces, is what makes possible the hydration of cells and tissues in living beings. Any factor that modifies the interaction of the proteins with water, the total or partial disappearance of this aqueous envelope or the breakdown of hydrogen bonds, will decrease its stability causing denaturation. Most proteins can be denatured when exposed to temperatures below $10^{\circ} \mathrm{C}$ and $15^{\circ} \mathrm{C}[21,22]$.

It has been reported that the vitrification of mature buffalo oocytes with $40 \%$ ethylene glycol (EG) or $40 \%$ DMSO, decreases morulae development rates up to $7.2 \%$ and $8 \%$, compared to those vitrified with a mixture of $20 \% \mathrm{EG}+\mathrm{DMSO}$ up to $11.5 \%$ [23], suggesting that the use of CPAs mixtures reduces the specific toxicity of each CPA and replaces it with denaturation associated with high concentrations of aggregates [22].

Studies in humans have shown that vitrification decreases the potential of internal membrane in oocytes in metaphase II (MII) [6,24]. In addition, by means of transmission electron microscopy, the fracture of the plasma membrane [25] and the zona pellucida has been observed, as well as the separation of cumulus-oocyte complexes (COCs) [26], the rupture of the communicating junctions between cells and the interruption or disappearance of microvilli, as well as drops of non-homogeneous lipids surrounding large vacuoles [26].

In oocytes and embryos, the fracture of the cell membranes is caused by the mechanical effect of the solutions solidification, and the critical temperature at which this damage occurs is between -50 and $-150^{\circ} \mathrm{C}$ [9]. It is important to highlight the importance of the structure and composition of the plasma membrane during the cryopreservation processes. Plasma membranes have proteins that can bind to other membrane components and cytoplasm proteins, in addition to other cellular structures such as the cytoskeleton, which is made up of microfilaments (MF), microtubules (MT), and intermediate filaments (IF) $[27,28]$.

Interactions between proteins associated with the plasma membrane could explain the changes in the polymerization and aggregation of temperature-dependent actin and MT, which is an important factor in the destabilization of the meiotic spindle and, therefore, of the disintegration of chromatin (CR) [21,22].

\section{Cytoskeleton}

Another important structure responsible for maintaining the structural and functional integrity of the oocyte is the cytoskeleton. The reorganization of this structure is involved in the communication between the oocyte and the cumulus cells during the maturation process, the fertilization in mammals [24,29,30,31,32], as well as in processes related to division and cell cycle, such as cytokinesis and karyokinesis. In addition, they participate in intracellular transport and constitute the spindle for chromosome segregation and centriole displacement during mitosis [33].

Studies in MII human oocytes report the reorganization of the cytoskeleton, in addition to the alteration in mitochondrial function without presenting any significant change in the configuration of meiotic spindle $[6,24]$, as well as depolymerization of tubulin [7]. Therefore, the association between chromosomes and the organization of MT during mitosis [34] is essential for oocyte maturation. In ovine, abnormal patterns were presented in the organization of the F-actin of the MII oocyte cytoskeleton exposed to CPAs and vitrified [35].

Laser scanning confocal microscopy (LSCM) examined the cytoskeleton and observed a considerable reduction of oocytes with spindles with normal chromosomes alignment in the equatorial plate after vitrification ( $79.5 \%$ fresh vs. $10.1 \%$ GV vitrified) [26]. Another study indicated that the meiosis stages in oocytes are related to temperature differences and equilibrium time of depolymerization and repolymerization of spindles, for example, telophase I (TI) has less depolymerization of spindles at room temperature, $4^{\circ} \mathrm{C}$ and after vitrification than those found in MI or MII [36]. In addition, the percentage of oocytes in GV and MII with normal distribution of F-actin is reduced after vitrification $(72.3 \%$ fresh vs. 16.9 and $37.2 \%$, respectively) [26].

The importance of the plasma membrane and the cytoskeleton of the oocyte during fertilization has been demonstrated, since it contains coupling receptors for sperm plasma membrane proteins, without which the recognition of gametes would not be possible [37].

\section{Genetic material damage}

CR configurations are important for meiotic resumption and competence in oocyte development. The genetic integrity and changes that occur in the cytoplasmic compartment have important implications for oocyte maturation and quality. MF, MT and CR interact in the segregation of chromosomes and in the establishment of the cellular asymmetry that allows the extrusion of the polar body with a minimal loss of cytoplasm [38].

Exogenous and endogenous factors may be responsible for causing damage to the oocytes genetic material, thereby compromising the success of ART. Several studies have reported the impact that DNA damage would cause throughout cell development [39-41], however, most of these studies have caused damage by exposing oocytes to physical or chemical stimuli, such as microhaz dissection laser (LMD) used in assisted reproduction and bleomycin (BLM) [42]. These studies have focused on analyzing the damage of double-strand break (DSB) of DNA, and although they did not implement vitrification, they did demonstrate the importance of the genetic integrity of the oocyte in cell development. 
One study performed in mice evaluated the effect that vitrification has on oocytes in MII and the resulting preimplantation embryos, it was measured the levels of reactive oxygen species (ROS), the accumulation of $\gamma$-H2AX (phosphorylation of histone variant $\mathrm{H} 2 \mathrm{AX}$ in serine 139) sensitive marker for DSB, apoptosis, percentage of early embryonic development and gene expression related to DNA damage (Brca1 and 53bp1) in early embryos derived from in vitro fertilization. It was found that vitrification increased the expression of $\gamma-\mathrm{H} 2 \mathrm{AX}$ in zygotes (in both pronuclei) and in embryos of two cells, but embryos of four and eight cells, as well as blastocysts were not affected. This was confirmed by Western blot analysis [43]. Because $\gamma-\mathrm{H} 2 \mathrm{AX}$ is not a sensitive marker for the analysis of DSB in MII oocytes, it was opted for the implementation of the Comet Assay as a method of damage analysis, in which they found no results that involved vitrification as a producer of DSB [43]. This may be due to the fact that the MII oocyte being transcriptionally inactive, requires the reserves of endogenous proteins and/or transcripts of mRNA accumulated during oogenesis for DNA repair and the preservation of the integrity of the maternal genome such as homologous recombination (HR) and the final nonhomologous union (NHEJ) [44].

The accumulation of $\gamma$-H2AX was attributed to the overproduction of ROS, because DNA damage can be induced by endogenous metabolites that may react with macromolecules such as lipids, proteins or nucleic acids, as well as exogenous stimuli such as ionizing and ultraviolet radiation, as is the production of ROS [43,45,46,47]. However, several studies report various functions related to the presence of $\gamma-\mathrm{H} 2 \mathrm{AX}$. Recent studies have shown that histone-H2AX phosphorylation $(\gamma-\mathrm{H} 2 \mathrm{AX})$ accumulates independently of the presence of DSB and functions as a regulator of cell cycle progression by inhibiting DNA replication, as well as to maintain the self-renewal of mouse embryonic stem cells [48-50].

It has been reported that exposure of porcine blastocysts to CPAs decreases survival rates, even without being vitrified, an increase in DNA fragmentation in the nuclei of these embryos was also found [51], thereby causing cytotoxic damage can be awarded to the exposure of the CPAs. This may be due to the fact that the cytotoxicity of these agents occurs in greater proportion in cells that perform a greater metabolic activity [52].

Through the analysis of DNA fingerprints based on microarrays, no evidence was found that vitrification of human MII oocytes increased the risk of aneuploidy production in arrested embryos than those properly obtained during an in vitro production system. Likewise, neither did the implantation potential decrease, however, IVF and viability were some of the factors that were affected [53]. Otherwise, in 2016, another study in humans found out that IVF rates were not affected by the vitrification of MII oocytes, however, embryonic development and viability were diminished due to this procedure. In the study by Forman et al. 2012, it was shown that there is no significant risk in the formation of aneuploidies caused by vitrification [54].
In both cases it can be explained that the percentage of IVF has not been affected because they used ICSI as a fertilization technique, which compensates for the disadvantage caused by vitrification with the hardening of the zona pellucida, which with a conventional fertilization would not be favored [55]. In addition, in both studies, oocytes were vitrified in the MII stage, in which the maternal genes are expressed and the embryos depend on the reserves of mRNA and the proteins stored in the cytoplasm of the oocyte, so, if they occur, some repair mechanism has already been activated when vitrification was performed [56]. However, it is not difficult to consider that the damage to the genetic material can cause genomic instability, leading to chromosomal aberrations such as aneuploidies.

\section{Aneuploidy formation}

Chromosomal abnormalities that occur in embryos are an important cause of pregnancy loss and greatly impair the normal ED and the fetus or lead to the birth of individuals suffering from various congenital abnormalities [57,58]. Structural and numerical chromosomal aberrations are important biological points in genotoxic studies. With the implementation of the fluorescent in situ hybridization (FISH) technique with chromosome-specific DNA probes, the sensitivity of detection of chromosomal aberrations can be increased.

Studies in farm animals are minimal compared to those in humans, however, numerical errors such as trisomy of particular chromosomes, monosomy of the $\mathrm{X}$ chromosome, polyploidy, as well as structural chromosomal abnormalities including Robertsonian translocations have been found in the number of chromosomes that arise from the union of two acrocentric chromosomes on a single metacentric (chromosome decreasing the haploid number) and reciprocals (segment exchange between two non-homologous chromosomes), or insertions similar to abnormalities present in humans [57-59].

The incidence and type of chromosomal abnormalities differ between gametes and embryos and even between species. In the pig there is a relatively high incidence of reciprocal translocations, in addition, the frequency of aneuploidy in oocytes or embryos varies due to different circumstances such as the different age of the animals used for experiments, methods used or by in vitro culture processes $[57,59]$. It was observed that, in early pig embryos obtained in vivo, 11 (14.3\%) of the 77 embryos examined had aneuploidies, in chromosomes 8, 11, 12, 13, 17 and $\mathrm{X}$ being the most frequent, contrary to chromosomes 2, 9 and 18 that presented a lower frequency of chromosomal errors [57].

This is important in experimental research, since most of the studies that evaluate aneuploidies as a result of the production of genetic damage derived from vitrification have been performed in humans [60-63], due to the importance it has in clinical application. This is possible thanks to the scientific progress that has achieved the characterization of the predominant diseases derived from aneuploidies and polyploidies. However, it is necessary to extend 
this knowledge in non-human species, since this can broaden the possibilities of the emergence of reproduction technologies in domestic species, which could also be applied in humans and that would have an advantage over the legal regulations involved in handling and experimentation with human cells.

\section{Discussion}

While it is true that the damage of oocytes and embryos caused by vitrification is produced, it is important to emphasize the lower cellular damage obtained by this technique compared to conventional slow freezing [9], so its use in ART remains promising. The vitrification of oocytes and embryos produces structural damage, which are inherent in the cytotoxicity of the CPA's used during the procedure. Several animal species and cell types have been studied (Table 1), in addition, the progress in microscopy has allowed the analysis and thus the implementation of various methodologies for its study. Some of these damages occur in the plasma membrane, the cytoskeleton and the genetic material, which result in the formation of aneuploidies in the resulting embryos (Table 1).

Table 1: Structural damage caused by vitrification in different species and meiotic stages.

\begin{tabular}{|c|c|c|c|c|c|}
\hline Specie & Meiotic Stage & Vitrification Device & Cellular Injury & Injury Analysis Method \\
\hline \multirow{2}{*}{ Human } & MII & McGill Cryoleaf & $\begin{array}{c}\text { Decreased inner membrane } \\
\text { potential. Cytosketetal } \\
\text { reorganization. Alteration of } \\
\text { mitochondrial function. }\end{array}$ & $\begin{array}{c}\text { Fluorescence } \\
\text { microscopy }\end{array}$ \\
\cline { 2 - 6 } & MII & Cryotop & Tubulin depolymerization. & Confocal microscopy \\
\hline \multirow{2}{*}{ Porcine } & GV, MII & $\begin{array}{c}\text { Open pulled straw } \\
\text { (OPS }\end{array}$ & $\begin{array}{c}\text { Spindles with misalignment of } \\
\text { chromosomes. } \\
\text { Abnormal distribution of } \\
\text { F-actin. }\end{array}$ & LSCM \\
\cline { 2 - 6 } & Blastocyst & None & Fragmented-DNA & TUNEL \\
\hline Ovine & MII & Cryotop & $\begin{array}{c}\text { Abnormal organization of } \\
\text { F-actin cytoskeleton. }\end{array}$ & Raman \\
\hline Mice & MI, MII & Cryotop & Spindles depolymerization. & $\begin{array}{c}\text { Fluorescence } \\
\text { microscopy }\end{array}$ \\
\hline
\end{tabular}

The increasing use of ART has increased the need to improve vitrification protocols, which although it is indisputable that they produce damage that naturally would not occur frequently, are necessary for the preservation of gametes, in particular the gamete female.

Derived from the need to continue implementing vitrification as one of the most used ART in clinical and experimental research, some alternatives have been considered to counteract the damage caused by this technique. As the use of glutathione (GSH) for the supplementation of the vitrification medium, which it has been observed that it promotes the development of mouse blastocysts derived from vitrified oocytes [64,65]. Resveratrol has been assigned the ability to decrease ROS levels, $\gamma$-H2AX accumulation and apoptotic production, in addition to improving embryonic development rates [43].

The importance of the structural integrity of the oocyte for the correct progressive development has been shown. Interactions between proteins associated with the plasma membrane play a crucial role in the polymerization and aggregation of the cytoskeleton protein structures. The polymerization of actin and microtubules will establish their distribution and rearrangement within the cell at different stages of development, participating in the stabilization of the meiotic spindle, therefore, the appropriate aggregation of chromatin. In addition to the presence of endogenous proteins and/or mRNA transcripts, such as HR and NHEJ, which participate in DNA repair and the preservation of the integrity of the maternal genome that can prevent the formation of chromosomal aberrations such as aneuploidies.

\section{Conclusion}

Oocytes and embryos manipulation, typical of the implementation of ART, results in structural and genetic changes have an impact on the normal cellular development. However, the need for the implementation of these technologies in society is increasing, not only for the application in human reproduction, but also for species of animals that coexist with it and that their manipulation represents an advantage for the human, either economically, production, research or preservation.

In order to guarantee the genetic maintenance of the individuals, the need to preserve the integrity, as much as possible, of the reserves of endogenous proteins and/or transcripts of mRNA of the oocytes for the repair of DNA is unquestionable, which is expected to result consequently in the integrity, proper functioning and correct distribution of other cellular structures such as cytoskeleton and plasma membrane. What will guarantee the progression of the cellular development of the oocytes produced in vitro until the ED, which not only must maintain the standards of development quality such as viability, maturation, IVF and ED, but guarantee the production of embryos that maintain their genetic integrity which will result in the implantation of the embryo, term pregnancy and the birth of offspring not only viable but with the absence of chromosomal aberrations that ensure an assertive and healthy development for the individual.

\section{Acknowledgement}

The authors thank Dr. Yvonne Ducolomb for her advice and motivation in carrying out this work. This study was financially 
supported by CONACyT (grant number 598630) to Alma López for Ph.D in Biological and Health Sciences..

\section{Conflicts of Interest}

No conflicts of interest.

\section{References}

1. Mullen SF, Fahy GM (2012) A chronologic review of mature oocyte vitrification research in cattle, pigs, and sheep. Theriogenology 78(8): 1709-1719.

2. Casillas F, Miguel Betancourt, Alma López, Lizbeth Juárez-Rojas, Socorro Retana-Márquez, (2016) State of the ART of slow freesing and vitrification of immature, mature oocytes and embryonic stages. International Journal of Current Research 8(07): 34737-34744.

3. Casillas F, Teteltitla-Silvestre M, Ducolomb Y, Lemus AE, Salazar Z, et al. (2014) Co-culture with granulosa cells improve the in vitro maturation ability of porcine immature oocytes vitrified with cryolock. Cryobiology 69(2): 299-304.

4. Fernandez-Reyez, F, Ducolomb Y, Romo S, Casas E, Salazar Z, et al. (2012) Viability, maturation and embryo development in vitro of immature porcine and ovine oocytes vitrified in different devices. Cryobiology 64(3): 261-266.

5. Hwang IS, Hochi S (2014) Recent Progress in Cryopreservation of Bovine Oocytes. BioMed Research International.

6. Lei T, Guo N, Liu JQ Tan MH, Li YF, et al. (2014) Vitrification of in vitro matured oocytes: effects on meiotic spindle configuration and mitochondrial function. Int J Clin Exp Pathol 3(7): 1159-1165.

7. Cubillos García S (2011) Confocal microscopy of the human egg meiotic spindle and its recovery time after vitrification. Mexican Journal of Reproductive Medicine 2(4): 63-67.

8. Kuleshova L, Lopata A (2002) Vitrification can be more favorable than slow cooling. Fertil Steril 78(3): 449-454.

9. Moussa M, Shu J, Zhang X, Zeng F (2014) Cryopreservation of mammalian oocytes and embryos: current problems and future perspectives. Sci China Life Sci 57(9): 903-914.

10. Rall WF, Fahy GM, (1985) Ice-free cryopreservation of mouse embryos at $-196^{\circ} \mathrm{C}$ by vitrification. Nature 313(6003): 573-575.

11. Cavusoglu T, Popken J, Guengoer T, Yilmaz O, Uyanikgil Y, et al. (2016) Ultra-Structural Alterations in In Vitro Produced Four-Cell Bovine Embryos Following Controlled Slow Freezing or Vitrification. 45(4): 291-307.

12. Bianchi V, Macchiarelli G, Borini A, Lappi M, Cecconi S, et al. (2014) Fine morphological assessment of quality of human mature oocytes after slow freezing or vitrification with a closed device: a comparative analysis. Reprod Biol Endocrinol 12: 110.

13. Khalili MA, Maione M, Palmerini MG, Bianchi S, Macchiarelli G, et al. (2012) Ultrastructure of human mature oocytes after vitrification. Eur J Histochem 56(3): e38.

14. Gualtieri R, Mollo V, Barbato V, Fiorentino I, Laccarino M, et al. Ultrastructure and intracellular calcium response during activation in vitrified and slow-frozen human oocytes. Human Reproduction 26(9): 2452-2460.

15. Rho GJ, Kim S, Yoo JG, Balasubramanian S, Lee HJ, et al. (2002) Microtubulin configuration and mitochondrial distribution after ultrarapid cooling of bovine oocytes. Mol Reprod Dev 63(4): 464-470.

16. Borini A, Coticchio G (2009) Preservation of human oocytes. Reproductive Medicine and Assisted Reproductive Techniques Series $1-13$.

17. Paynter SJ, Cooper A, Gregory L, Fuller BJ, Shaw RW (1999) Permeability characteristics of human oocytes in the presence of the cryoprotectant dimethylsulphoxide. Human Reproduction 14(9): 2338-2342.

18. Chian RC, (2010) Cryobiology: an overview. En Fertility Cryopreservation. $1^{\text {st }}$ edition Cambridge University Press 1-9.
19. Ávila-Portillo LM, (2006) Fundamentals of cryopreservation. Colombian Journal of Obstetrics and Gynecology 57(4): 291-300.

20. Gurtovenko A Anwar J, (2007) Modulating the Structure and Properties of Cell Membranes: The Molecular Mechanism of Action of Dimethyl Sulfoxide. The Journal of Physical Chemistry (35): 10453-10460.

21. Fahy G, Wowk B (2015) Principles of cryopreservation by vitrification. En Methods in molecular biology. Clifton NJ $1257: 21-82$.

22. Fahy G (2016) Overview of biological vitrification. En Vitrification in assisted reproduction, $2^{\text {nd }}$ edition RM\&ART, 35: 1-22.

23. Gautam SK, Verma V, Palta P, Chauhan MS, Manik RS (2008) Effect of type of cryoprotectant on morphology and developmental competence of in vitro matured buffalo (Bubalus bubalis) oocytes subjected to slow freezing or vitrification. Reproduction, Fertility and Development 20(4): 490-496.

24. Suzuki H, Saito Y, Kagawa N, Yang X (2003) In vitro fertilization and polyspermy in the pig: factors affecting fertilization rates and cytoskeletal reorganization of the oocyte. Microsc Res Tech 61(4): 327-334.

25. Zhou GB, N Li (2009) Cryopreservation of porcine oocytes: recent advances. Mol Hum Reprod 15(5): 279-285.

26. Wu C, Rui R, Dai J, Zhang C, Ju S, et al. (2006) Effects of cryopreservation on the developmental competence, ultrastructure and cytoskeletal structure of porcine oocytes. Mol Reprod Dev 73(11): 1454-1462.

27. Cereijido M, Contreras RG, Shoshani L, Ponce A (2003) The cell membrane in cellular and molecular biology $1^{\text {st }}$ ed. Pearson Education of Mexico 151-193.

28. Reece JB, Urry LA, Cain ML, Wasserman SA, Minorsky PV, et al. (2011) Membrane structure and function. En Campbell biology, $10^{\text {th }}$ ed CA Pearson 124-140.

29. Suzuki H, Jeong BS, Yang X (2000) Dynamic changes of cumulus-oocyte cell communication during in vitro maturation of porcine oocytes. Biology Reproduction 63(3): 723-729.

30. Suzuki H, Takashima Y, Toyokawa K (2002) Cytoskeletal organization of porcine oocytes aged and activated electrically or by sperm. Journal of Reproduction and Development 48: 293-301.

31. Suzuki H, Saito Y, Kagawa N, Yang X (2003) In vitro fertilization and polyspermy in the pig: factors affecting fertilization rates and cytoskeletal reorganization of the oocyte. Microscopy Research and Technique 61(4): 327-334.

32. Bogliolo L, Murrone O, Piccinini M, Ariu F, Ledda S, et al. (2015) Evaluation of the impact of vitrification on the actin cytoskeleton of in vitro matured ovine oocytes by means of Raman microspectroscopy. Journal of Assisted Reproduction and Genetics 32(2): 185-193.

33. Benítez G, González A, Meza I (2003) The cytoskeleton. In cellular and molecular biology, 1st ed. Pearson Education of Mexico 273-292.

34. Sun QY, Lai L, Wu GM, Park KW, Day BN, et al. (2001) Microtubule assembly after treatment of pig oocytes with Taxol: correlation with chromosomes, gama-tubulin, and MAP Kinase. Molecular Reproduction and Development 60(4): 481-490.

35. Bogliolo L, Murrone O, Piccinini M, Ariu F, Ledda S, et al. (2015) Evaluation of the impact of vitrification on the actin cytoskeleton of in vitro matured ovine oocytes by means of Raman microspectroscopy. J Assist Reprod Genet 32(2): 185-193.

36. Gomes C, Merlini M, Konheim J, Serafini P, Motta EL, et al. (2012) Oocyte meiotic-stage-specific differences in spindle depolymerization in response to temperature changes monitored with polarized field microscopy and immunocytochemistry. Fertil Steril 97(3): 714-719.

37. Berger T, Nitta BJ, Ducolomb Y, Betancourt M (2011) Interaction of potential porcine sperm ligands with the oocyte plasma membrane. Reprod Domest Anim 46(1): 15-20.

38. Coticchio G, Dal Canto M, Mignini Renzini M, Guglielmo MC, Brambillasca $\mathrm{F}$, et al. (2015) Oocyte maturation:gamete-somatic cells interactions, meiotic resumption, cytoskeletal dynamics and cytoplasmic reorganization. Human Reproduction Update 21(4): 427-454. 
39. Wang H, Yibo L, Ming-Hui Z, Zili L, Jeongwoo K, et al. (2016) DNA DoubleStrand Breaks Disrupted the Spindle Assembly in Porcine Oocytes. Molecular Reproduction \& Development 83(2): 132-143.

40. Collins JK, Keith T Jones (2016) DNA damage responses in mammalian oocytes. Reproduction. 152(1): R15-22.

41.Zhang T, Zhang GL, Ma JY, Qi ST, Wang ZB, et al. (2014) Effects of DNA damage and short-term spindle disruption on oocyte meiotic maturation. Histochem Cell Biol 142(2):185-194.

42. Ma JY, Ou Yang YC, Wang ZW, Wang ZB, Jiang ZZ, et al. (2013) The effects of DNA double-strand breaks on mouse oocyte meiotic maturation. Cell cycle 12(8): 1233-1241.

43. Chang H, Chen H, Zhang L, Wang Y, Xie X, et al. (2019) Effect of oocyte vitrification on DNA damage in metaphase II oocytes and the resulting preimplantation embryos. Mol Reprod Dev 86(11): 1603-1614.

44. Martin JH, Bromfield EG, Aitken RJ (2018) Double Strand Break DNA Repair occurs via Non-Homologous End-Joining in Mouse MII Oocytes. Sci Rep 8(9685).

45. Gupta S, Sekhon L, Kim Y, Agarwal A (2010) The role of oxidative stress and antioxidants in assisted reproduction. Current women`s health reviews 6: 227-238.

46. Agarwal A, Tamer M, Bedaiwy MA, Banerjee J, Alvarez JG (2006) Oxidative stress in an assisted reproductive technique setting. Fertility and Sterility 86(3): 503-512.

47. Agarwal A, Allamaneni S (2004) Role of free radicals in female reproductive diseases and assisted reproduction. Reproductive Biomedicine online 9(3): 338-347.

48. Turinetto V, Orlando L, Sanchez-Ripoll Y, Kumpfmueller B, Storm MP, et al. (2012) High basal $\gamma \mathrm{H} 2 \mathrm{AX}$ levels sustain self-renewal of mouse embryonic and induced pluripotent stem cells. Stem cells 30(7): 14141423.

49. Fernando R, Eleuteri B, Abdelhady S, Nussenzweig A, Andang M, et al. (2011) Cell cycle restriction by histone H2AX limits proliferation of adult neural stem cells. Proceedings of the National Academy of Sciences 108(14): 5837-5842

50. Andäng M, Hjerling-Leffler J, Moliner A, Lundgren TK, Castelo-Branco $G$, et al. (2008) Histone H2AX-dependent GABAA receptor regulation of stem cell proliferation. Nature 451: 460-464.

51. Rajaei F, Karja NW, Agung B, Wongsrikeao P, Taniguchi M, et al. (2005) Analysis of DNA fragmentation of porcine embryos exposed to cryoprptectans. Reprod Dom Anim 40(5): 429-432.

52. Lawson AH, Ahmad, Sambanis A (2011) Cytotoxicity effects of cryoprotectants as single-component and cocktail vitrification solutions. Cryobiology 62(2): 115-122.

53. Forman E, Li X, Ferry K, Scott K, Treff NR, et al. (2012) Oocyte vitrification does not increase the risk of embryonic aneuploidy or diminish the implantation potential of blastocysts created after intracytoplasmic sperm injection: a novel, paired randomized controlled trial using DNA fingerprinting. Fertility and sterility 98(3): 644-649.

54. Sun Y, Gu R, Lu X, Zhao S, Feng Y (2016) Vitrification of in vitro matured oocytes diminishes embryo development potential before but not after embryo genomic activation. J Assist Reprod Genet 3(2): 231-236.

55. Casillas F, Ducolomb Y, Lemus AE, Cuello C, Betancourt M (2015) Porcine embryo production following in vitro fertilization and intracytoplasmic sperm injection from vitrified immature oocytes matured with a granulosa cell co-culture system. Cryobiology 71(2): 299-305.

56. Vassena R, Boué S, González-Roca E, Aran B, et al. (2011) Waves of early transcriptional activation and pluripotency program initiation during human preimplantation development. Development 138(17): 36993709.

57. Hornak M, Oracova E, Hulinska P, Urbankova L, Rubes J (2012) Aneuploidy Detection in Pigs Using Comparative Genomic Hybridization: From the Oocytes to Blastocysts. PLoS ONE 7(1): e30335.

58. Hornak M, Hulinska P, Musilova P, Kubickova S, Rubes J (2009) Investigation of Chromosome Aneuploidies in Early Porcine Embryos Using Comparative Genomic Hybridization. Cytogenetic Genome Research 126(1-2): 210-216.

59. Zhang Z, Wang T, Hao Y, Panhwar F, Chen Z, et al. (2017) Effects of trehalose vitrification and artificial oocyte activation on the development competence of human immature oocytes. Cryobiology 74: 43-49.

60. Minasi M, Fiorentino F, Ruberti A, Biricik A, Cursio E, et al. (2017) Genetic diseases and aneuploidies can be detected with a single blastocyst biopsy: a successful clinical approach. Human Reproduction 32(8): 1770-1777.

61. Capalbo A, Rienzi L, Cimadomo D, Maggiulli R, Elliott T, et al. (2014) Correlation between standard blastocyst morphology, euploidy and implantation: an observational study in two centers involving 956 screened blastocysts. Human Reproduction 29(6): 1173-1181.

62. Fiorentino F, Bono S, Biricik A, Nuccitelli A, Cotroneo E, et al. (2014) Application of next-generation sequencing technology for comprehensive aneuploidy screening of blastocysts in clinical preimplantation genetic screening cycles, Human Reproduction 29(12): 2802-2813.

63. Baart EB, Van Opstal D, Fauser FJ, BCJM Martini E (2004) Fluorescence in situ hybridization analysis of two blastomeres from day 3 frozenthawed embryos followed by analysis of the remaining embryo on day 5 . Human Reproduction. 19(3): 685-693.

64. Zhou C, Zhang X, Chen Y, Liu X, Sun Y, et al. (2019) Glutathione alleviates the cadmium exposure-caused porcine oocyte meiotic defects via eliminating the excessive ROS. Environmental Pollution 255(1): 113194.

65. Moawad AR, Tan SL, Taketo T (2017) Beneficial effects of glutathione supplementation during vitrification of mouse oocytes at the germinal vesicle stage on their preimplantation development following maturation and fertilization in vitro. Cryobiology 76: 98-103. 